\title{
Adrenal Crisis
}

National Cancer Institute

\section{Source}

National Cancer Institute. Adrenal Crisis. NCI Thesaurus. Code C112840.

A life threatening condition due to inadequate levels of glucocorticoids in an individual with adrenal insufficiency. 